\title{
Sınıf Öğretmeni Adaylarının Epistemolojik İnançlarının ve Üst- Bilişlerinin Teknolojiye Yönelik Tutumlarına Katkısı
}

Yunus KARAKUYU*

Akın KARAKUYU*

\section{Öz}

Teknoloji kullanımının çı̆̆ gibi yaygınlaştığı günümüzde teknolojiyi eğitim ortamına transfer edecek olanlar öğretmenlerdir. Öğretmenlerin teknolojiyi eğitim öğretimde kullanabilmeleri için öncelikle kendilerinin teknolojiye karşı olumlu bir tutum geliştirmeleri gerekir. Öğretmen adaylarının teknolojiye karşı tutumlarını etkileyebilecek birçok faktör vardır. Bunlardan biri normal bilişsel stratejilerin daha üstünde olan ve bireyin bilgiyi edinme sürecindeki olayların farkında olmasını sağlayan üst-biliş, bir diğeride bireylerin bilgiye yönelik inançlarını ifade eden epistemolojik inançlarıdır.

Bu çalışmada sınıf öğretmeni adaylarının epistemolojik inançlarının ve üst-bilişlerinin teknolojiye karşı tutumlarına katkısını incelemek amaçlanmış olup, tarama modelinde bir çalışmadır. Veriler üç farklı üniversitenin eğitim fakültesinin son sınıfında öğrenim gören 331 sınıf öğretmeni adaylarından toplanmıştır. Öğretmen adaylarına teknoloji tutum, epistemolojik inanç ve üst-biliş ölçekleri uygulayarak toplanan veriler çoklu eş zamanlı ve hiyerarşik regresyon analizi ile test edilmiştir.

Analiz sonuçlarına göre epistemolojik inançların ve üst-bilişin sınıf öğretmeni adaylarının teknolojiye karşı tutumlarını tahmin etmede istatiksel olarak anlamlı bir katkısı vardır. Ayrıca ayarlanmış $R^{2}$ değerinin 0,227 olması öğretmen adaylarının teknolojiye karşı tutumlarındaki değişimin \%22,7 nin epistemolojik inanç ve üst-biliş değişkenlerince açıklandığının bir göstergesidir.

Anahtar Kelimeler: Teknolojiye Yönelik Tutum, Üst-biliş, Epistemolojik İnanç, Sınıf Öğretmeni Adayı.

${ }^{*}$ Doç.Dr., Uşak Üniversitesi

** Öğr.Gör. Mustafa Kemal Üniversitesi 


\title{
The Contribution of Epistemological Beliefs and Metacognition on Pre- Service Primary School Teachers' Technological Attitude
}

\begin{abstract}
Using technology increases day by day very fast and teachers will transfer it to training environment. In order to use technology in education and training, first teachers must develop a positive attitude towards the technology themselves. There are many factors which can be affect preservice teachers' attitudes towards technology. One of them is metacognition that is higher than the normal cognitive strategies and provide to be aware of events in the process of the information and the other is epistemological beliefs that is expressing individuals' faith towards knowledge.

Purpose of this study is to examine the contribution of epistemological beliefs and metacognition to the technological attitude of pre-service primary school teachers'. This is a research-based study. Data are gathered by applying technological attitude, metacognition and epistemological beliefs scales on 331 students from 3 different faculty of educations. Multiple regression analysis is used to analyze data.

According to the results, epistemological beliefs and metacognition has a statistically significant contribution to the prediction of technological attitude of pre-service primary school teachers'. Additionally, the fact that the adjusted $\mathrm{R}^{2}$ value was 0,227 shows that $22,7 \%$ of the change in preservice teachers' technological attitude is explained within the independent variables.

Keywords: Attitude towards Technology, Metacognition, Epistemological Beliefs, Pre-service Primary School Teachers.
\end{abstract}

\section{Giriş}

Günümüzde teknolojiyi kullanmak bir ayrıcalıktan ziyade zorunluluk haline gelmiştir. $\mathrm{Bu}$ durum teknolojinin birçok alanda kullanılmasını sağlamıştır. Bu alanlardan biride eğitimdir. Teknolojiyi kullanabilmek için öncelikle o teknolojiyi ile alakalı bilgi, beceri ve tutum kazanmak gerekir.

Eğitim sistemimizin en önemli ögelerinden biri şüphesiz öğretmenlerimizdir. Dolayısıyla teknolojinin eğitim-öğretim ortamında kullanılmasında öğretmenlerin rolü büyüktür. Oktay ve Çakır (2012)'e göre, öğretmenlerin teknolojiye karşı tutumu öğrencilerin tutumunu bu da toplumun teknolojiye karşı tutumunu doğrudan değiştirecektir. İçinde 
yaşadığımız bu zamanda öğretmenlerin hem teknolojiyi kullanması hem de öğrenciye teknolojiyi öğrenme amaçlı nasıl kullanacaklarını öğretebilecek yeterliğe sahip olmalıdırlar (Koç, 2004).

Milli Eğitim Bakanlığı (MEB) eğitimde teknolojinin kullanılması adına çeşitli çalışmalar ve yatırımlar yapmaktadır. MEB 2010-2014 stratejik planında, Hayat Boyu Öğrenme ve Bilgi Toplumu Projesi kapsamında teknoloji okuryazarlığı temasını işlemiştir. Ayrıca MEB tarafından yürütülüp, Ulaştırma Bakanlığı tarafından desteklenen Eğitimde FATïH (Fırsatları Artırma ve Teknolojiyi İyileştirme Hareketi) projesi başlatılmıştır. $\mathrm{Bu}$ projelerin başarılı olabilmesi için öğretmenlerin sınıflarında teknolojiyi etkin bir şekilde kullanmaları gerekir.

Öğrencilerin hem okulda hem de mezun olduktan sonraki iş ve sosyal yaşantılarında teknolojiyi kullanabilmeleri ve bu sayede çağ yakalayabilmeleri için daha eğitim döneminde teknolojiye karşı olumlu bir tutum kazanabilmelerine bağlıdır. Özellikle sınıf öğretmenlerinin eğitim öğretim hayatına yeni başlayan öğrencilere teknolojiyi kullanabilme tutumu kazandırması bu açıdan önemlidir.

Yeni teknolojilerin eğitim alanına entegre edilerek kullanılması, eğitim öğretim kalitesinin yükseltilmesi açısından son derece önemlidir. Eğitimde çağdaş teknolojinin kullanılması, öğrencilerin daha kolay, daha hızlı öğrenmelerini, aynı zamanda öğretmenlerin iş doyumunu sağlayacaktır. Çağdaş eğitimde öğretmen ve teknolojinin birbirini tamamlaması, eğitim öğretimde kalitenin artmasına yardımcı olacaktır (Ozan, 2009). Öğretmen adaylarının mesleki hayatlarında istenilen düzeyde başarıya ulaşabilmeleri için öncelikle teknolojinin eğitimdeki önemini kabul etmeleri ve kullanabilme becerisine sahip olmaları gerekmektedir. Çünkü öğretmen adayları göreve başladıklarında teknoloji ile iç içe olan öğrenci grubu ile karşılaşacaklardır (Erdemir, Bakırcı ve Eyduran, 2009). İçinde yaşadığımız yüzyıl bilgi çağıdır bunun sebeplerinden biride teknolojinin gelişmesi sonucu bilgiye artık kolayca ulaşılabilmesidir. Bu sayede yaşam boyu öğrenme diye bir kavram ortaya çıkmıştır. Teknoloji hem okul hem okul dışında çocuk ve yetişkinlerin eğitiminde kullanıldığından yaşam boyu öğrenme teknolojinin kullanılması ile sağlanabilir (Öztürk ve Horzum, 2011). Okulların amacı çağın koşullarına uygun bireyler yetiştirmek olduğundan, buralarda kullanılan yöntem ve teknikler öğrencilerin bilişsel, duyuşsal, psikomotor becerilerine fizyolojilerine de uyumlu olmalıdır (Oktay ve Çakır, 2013). Bunu da öğretmenler teknolojiye karşı olumlu bir tutum geliştirerek ve derslerine en uygun teknolojiyi seçerek sağlayabilirler.

Yıldırım (2007) yaptığı çalışmada öğretmenlerin teknolojiyi öğrencilerin öğrenmelerini desteklemek yerine derse hazırlık aşamasında 
çalışma kâğıtları ve sınavlar oluşturmak için kullandıklarını ve öğretmenlerin hizmet içi eğitim eksikleri ve üniversitede aldıkları eğitimin yeterli olmaması nedeniyle teknolojiyi eğitime adapte etmekte zorlandıklarını ifade etmiştir.

Öğretmen adaylarının çağın gereklerine ve niteliklerine uygun birer öğretmen olabilmeleri için teknolojiye karşı tutumları son derece önemlidir. $\mathrm{Bu}$ bağlamda öğretmen adaylarının teknolojiye karşı tutumlarını olumlu veya olumsuz yönde etkileyen faktörleri belirlemek gerekir. Bu faktörlerden biri öğretmen adaylarının epistemolojik inançları bir diğeri de üstbilişleridir.

Bireylerdeki, bilginin doğası ve bilme eyleminin nasıl gerçekleştiğine yönelik inançlar epistemolojik inanç olarak ifade edilmektedir. Sahip olunan bu inançlar gelişmiş ve gelişmemiş olarak sınıflandırılmaktadır. Gelişmemiş epistemolojik inanca sahip olan bireyler bilginin basit, mutlak bir doğrudan oluştuğu ve bir otorite tarafından aktarıldığına inanmışlardır. Gelişmiş bir epistemolojik inanca sahip olan bireyler bilginin daha karmaşık, göreceli ve bulunduğu koşullara göre değişebileceğine inanmışlardır. Ayrıca bir otorite tarafından aktarılmış bilgiler değil de sosyal etkileşimlere dayalı olarak sürekli değişen bir yapı olduğuna inanmaktadırlar (Bromme, Pieschl ve Stahl, 2010).

Bilginin etkin bir çaba sonucunda kazanıldığına dair oluşmuş olumlu bir inanç, bireylerde kendi düşünme sürecine yoğunlaşabilmelerini, ihtiyaç duyduğu öğrenme yollarını seçebilmelerini, içsel enerjilerini harekete geçirmelerini, yapacakları etkinlikleri planlama ve değerlendirmelerini de beraberinde getirecektir (Demir ve Doğanay, 2009).

Öğrenciler açısından bakılırsa, gelişmiş epistemolojik inanca sahip olan bireyler öğrenme sürecinde daha fazla nitelikli bilişsel stratejileri kullanmakta, bilişüstü öğreti materyallerini daha sık ve doğru biçimde denetleyebilmekte, daha yüksek düzeyde akademik başarı göstermekte ve okula yönelik olumlu tutum sergilemekle birlikte eğitimin yararına daha fazla inanmaktadırlar (Deryakulu ve Büyüköztürk, 2005).

Üstbiliş, normal bilişin üstü olarak nitelenen bilinçli bilme ve düşünme şekli, farkındalık düzeyi veya düzenleme yeteneği olarak ifade edilebilir (Baltacı ve Akpınar, 2011). Bilişsel beceriler bir görevi yerine getirmek için kullanılırken, bilişüstü becerileri o görevin nasıl yerine getirileceğinin anlaşılması konusunda devreye girmektedir (Bedel ve Çakır, 2013).

Bilişüstü özelliklere yüksek düzeyde sahip olan bireylerde; nasıl düşündüğünü düşünme, sorun çözme aşamasında tüm olasılıkları göz önünde bulundurma, düşünme ve öğrenme sürecinde güçlü ve güçsüz 
yanlarının farkında olma, kendini izleme ve öz değerlendirmesini yapabilme gibi özellikler görülmektedir (Sapanc1, 2012). Gourgey (2002)'e göre üstbiliş kişinin bilgisini kullanırken stratejik davranmasına ve en etkili performansını sergilemesini sağlar. Bu yüzden okullarda eğitim amaçlı kullanılacak yöntemlere teknolojiyi entegre edildiği zaman çağımızın gerektirdiği becerilere sahip insanlar yetiştirmek mümkün olacaktır.

\section{Yöntem}

\section{Araştırmanın Amacı}

Çalışmamızda sınıf öğretmeni adaylarının teknolojiye karşı tutumlarına katkı sağlayabilecek faktörlerden üst-biliş ve epistemolojik inançların katkısını incelemek amaçlanmıştır.

\section{Araştırmanın Önemi}

Teknoloji her alanda olduğu gibi eğitim öğretim alanında da yaygın bir şekilde kullanılmalıdır. Bunun önşartı ise öğretmenlerin teknolojiye karşı belirli bir seviyede bilgi ve tutumlarının olmasıdır. Bu sebeple, normal bilişsel stratejilerden daha üst konumda olan bilgiyi edinme sürecindeki olayların farkında olmasını sağlayan üst-biliş ve bu bilgiyi edinme sırasında öğretmen adaylarının bilgiye yönelik inanışlarını ifade eden epistemolojik inançlar önemlidir. Özellikle eğitim sistemimizin temel taşını oluşturabilecek olan sınıf öğretmeni adaylarının teknolojiye karşı tutumlarına katkısı olabilecek bu faktörleri belirlemek önemlidir.

\section{Araștırmanın Yöntemi}

Bu araştırmada, tarama yöntemi kullanılmıştır. Tarama yöntemi, geçmişte veya halen var olan bir durumu var olduğu şekliyle betimlemeyi amaçlayan araştırma yaklaşımıdır (Karasar, 2000).

\section{Çalışma Grubu}

Araştırmanın çalışma grubunu uygun örnekleme yöntemiyle üç farklı üniversitenin eğitim fakültesi sınıf öğretmenliği son sınıfında öğrenim gören 331 sınıf öğretmeni adayı oluşturmaktadır.

\section{Veri Toplama Araçları}

Teknoloji Tutum Ölçeği (TTÖ): Araştırmada, veri toplamak amacıyla, Yavuz (2005) tarafından geliştirilen ve geçerlik güvenirlik çalışması yapılan “Teknoloji Tutum Ölçeği” kullanılmıştır. Ölçek 5’li Likert yapıda olup 19 maddeden oluşmaktadır. Ölçekten alınabilecek en düşük puan 19 , en yüksek puan ise 95 'dir. "Teknolojik araçların eğitim alanında 
kullanılmama durumu, teknolojik araçların eğitim alanında kullanılma durumu, teknolojinin eğitim yaşamına etkileri, teknolojik araçların kullanımının öğretilmesi ve teknolojik araçların değerlendirmesi" isimli beş alt faktörden oluşan ölçeğin güvenirlik katsayısı 0.8668 olarak belirlenmiştir.

Üst biliş Etkinlik Ölçeği (ÜBÖ): Orijinali Cooper, Urena ve Stevens (2008) tarafından geliştirilen ölçek Tüysüz, Karakuyu ve Bilgin (2008) tarafından Türkçeye çevrilerek adaptasyonu yapılmış ve cronbach $\alpha$ - iç tutarlık katsayısı 0,783 olarak belirlenmiştir. Ölçek 27 madde ve tek boyutlu olup, ölçekten alınabilecek en düşük puan 27, en yüksek puan ise 135 dir.

Epistemolojik İnançlar Ölçeği (EïÖ): Elder (1999) tarafından Bilimsel Epistemolojik İnanç ölçeğinin Türk Kültürüne uyarlaması Acat, Tüken ve Karadağ tarafından gerçekleştirilmiştir. Ölçeğin cronbach alpha katsayısı 0.82 olarak hesaplanmıştır. Ölçekten alınabilecek en düşük puan 25, en yüksek puan ise 125 dir. Ölçek "otorite ve doğruluk", "bilgi üretme süreci", "bilginin kaynağı", akıl yürütme" ve "bilginin değişirliği" şeklinde beş alt boyut ve 25 maddeden oluşmaktadır.

\section{Verilerin Analizi}

Öğrencilerden toplanan veriler SPSS programı ile analiz edilmiştir. Bağımlı ve bağımsız değişkenler arasındaki korelasyon katsayısı için pearson korelasyon analizi ve her bir bağımsız değişkenin bağımlı değişkene katkısı çoklu eş zamanlı ve hiyerarşik regresyon analizi ile test edilmiştir.

\section{Bulgular}

Araştırmada etkisi araştırılan değişkenler arasında ilişki olup olmadığı varsa ilişkinin düzeyini belirlemek amacıyla pearson korelasyon analizi yapılmış ve elde edilen bulgular tablo-1'de sunulmuştur.

Tablo 1. Sınıf Öğretmeni Adaylarının Bağımlı Ve Bağımsız Değişlerden Aldıkları Puanların Korelasyon Kat Sayıları

\begin{tabular}{lcc}
\hline & Bağımsız & Değişkenler \\
Bağımlı Değişken & Epistemolojik İnanç & Üst-biliş \\
\hline Teknoloji Tutum & $0,407^{* *}$ & $0,292^{* *}$ \\
Bağımsı Değişkenler & & \\
Epistemolojik İnanç & ----- & 0,89 \\
Üst-biliş & & ------ \\
\hline
\end{tabular}

$\mathrm{N}=331 ;{ }^{* * \mathrm{P}<0,01}$ 
Analiz sonuçları sınıf öğretmeni adaylarının teknoloji tutum ölçeğinden aldıkları puanların ortalamaları ile epistemolojik inançlar $(\mathrm{r}=$ 0,407 ; $\left.{ }^{* *} \mathrm{P}<0,01\right)$ ve üst biliş $\left(\mathrm{r}=0,292 ;{ }^{* * \mathrm{P}}<0,01\right)$ ölçeklerinden aldıkları puanların ortalamaları arasında istatiksel olarak anlamlı bir ilişki olduğunu göstermektedir.

Eş zamanlı çoklu regresyon analizinde tahmin değişkenleri olan, üst biliş ve epistemolojik inançlar dikkate alındığında, bu değişkenlerin bağımlı değişken olan sınıf öğretmeni adaylarının teknoloji tutumlarını tahmin etmedeki katkılarının istatistiksel olarak anlamlı olduğu bulunmuştur ( $\mathrm{F}(2$, $330)=49,432, \mathrm{P}<0,01)$.

Sınıf öğretmeni adaylarının teknolojiye karşı tutumlarını tahmin etmede kullanılan üst biliş ölçeği ve epistemolojik inançlar ölçeği sonuçlarının eş zamanlı çoklu regresyon analiz sonuçları Tablo 2 de verilmiştir.

Tablo 2. Sınıf Öğretmeni Adaylarının Teknolojiye Yönelik Tutumlarının Eş Zamanlı Çoklu Regresyon Analiz Sonuçları

\begin{tabular}{llccccc}
\hline Değişkenler & $\mathrm{B}$ & $\mathrm{t}$ & $\mathrm{p}$ & Adj R & $\mathrm{F}$ & $\mathrm{p}$ \\
\hline Epistemolojik İnanç & 0,357 & 7,896 & 0,00 & & & \\
Üst-biliş & 0,241 & 5,320 & 0,00 & 0,227 & 49,32 & 0,00 \\
& & & & & & \\
Sabit & 39,848 & 7,560 & & & & \\
\hline
\end{tabular}

Not: B, regresyon kat sayısı; Çoklu $R=0,481, R^{2}=0,232$, ayarlanmış $R^{2}=$ 0,227. ${ }^{* *} \mathrm{P}<0,01$

Tablo 2'de görüldüğü gibi bağımsız değişkenler analizde yer aldığında epistemolojik inançlar ve üst-bilişin öğretmen adaylarının teknolojiye karşı tutumlarını tahmin etmede istatistiksel olarak anlamlı bir katkısı vardır. Ayarlanmış $\mathrm{R}^{2}$ 'nin değerinin 0,227 olması, sınıf öğretmeni adaylarının teknolojiye karşı tutumlarındaki değişimin \%22,7'sinin bağımsız değişkenlerce açıklandığının bir göstergesidir.

Tablo 3. Epistemolojik İnançlar Değiş̧keni İçin Regresyon Analiz Sonuçları

\begin{tabular}{lclc}
\hline Değişken & $\mathrm{B}$ & SHB & $\beta$ \\
\hline Epistemolojik İnanç & 0,378 & 0,047 & $0,407^{* * *}$ \\
Sabit & 61,344 & 3,421 & \\
\hline
\end{tabular}

Not: $B$, regresyon kat sayısi; SHB, B deki standart hata; $\beta$, standart regresyon kat sayısı. Çoklu $R=0,407, R^{2}=0,165$, ayarlanmış $R^{2}=0,163$. ${ }^{* *} P<0,01$ 
Tablo 4. Üst-biliş Değişkeni İçin Regresyon Analiz Sonuçları

\begin{tabular}{lccc}
\hline Değişken & B & SHB & $\beta$ \\
\hline Üst-biliş & 0,272 & 0,049 & $0,292^{* *}$ \\
Sabit & 62,299 & 4,755 & \\
\hline
\end{tabular}

Not: $\mathrm{B}$, regresyon kat sayıs1; $\mathrm{SHB}, \mathrm{B}$ deki standart hata; $\beta$, standart regresyon kat sayısı. Çoklu $R=0,481, R^{2}=0,086$, ayarlanmış $R^{2}=0,083$. * $P<0,01$

Tablo 3 ve $4^{\prime}$ te görüldüğü gibi ayarlanmış $R^{2}$ değerinin bağımsız değişkenler için ayrı ayrı ele alındığında ise epistemolojik inançlar ölçeği için 0,163 olması sınıf öğretmeni adaylarının teknolojiye karşı tutumlarındaki değişimin \%16,3 nün bu tahmin değişkeninden kaynaklandığını, ayarlanmış $R^{2}$ değerinin üst-biliş ölçeği için 0,083 olması sınıf öğretmeni adaylarının teknolojiye karşı tutumlarındaki değişimin \%8,3 nün bu tahmin değişkeninden kaynaklandığının bir göstergesidir.

Bağımsız değişkenlerden epistemolojik inançlar için alt boyutları da dikkate alınarak hiyerarşik çoklu regresyon analizi yapılmıştır. Epistemolojik inançlar ölçeğinin alt boyutlarının bağımlı değişken olan teknolojiye karşı tutumla aralarındaki korelasyon sonuçları Tablo 5'te verilmiştir.

Tablo 5. Sınıf Öğretmeni Adaylarının Teknolojiye Karşı Tutumlarının Ve Epistemolojik İnançlar Ölçeği Alt Boyutlarından Aldıkları Puanlarının Korelasyon Analizi Sonuçları

$$
\text { Epistemolojik İnançlar Ölçeği alt Boyutları }
$$

\begin{tabular}{lccccc} 
Bağımlı Değişken & 1 & 2 & 3 & 4 & 5 \\
\hline $\begin{array}{l}\text { Teknolojiye Karşı Tutum } \\
\text { Ė̈Ö alt boyutları }\end{array}$ & $0,294^{* *}$ & $0,326^{* *}$ & $0,324^{* *}$ & $0,367^{* *}$ & $0,268^{* *}$ \\
1. Otorite ve Doğruluk & ---- & $0,294^{* *}$ & $0,574^{* *}$ & $0,602^{* *}$ & $0,568^{* *}$ \\
2. Bilgi Üretme Süreci & & ----- & $0,386^{* *}$ & $0,362^{* *}$ & $0,394^{* *}$ \\
3. Bilginin Kaynağ1 & & & ------- & $0,684^{* *}$ & $0,790^{* *}$ \\
4. Akıl Yürütme & & & ------ & $0,608^{* *}$ \\
5. Bilginin Değişirliği & & & & ----- \\
\hline $\mathrm{N}=331 ;{ }^{* *} \mathrm{P}<0,01$ & & & &
\end{tabular}


Analiz sonuçları sınıf öğretmeni adaylarının teknolojiye karşı tutum ölçeği puanlarının ortalamaları ile epistemolojik inançlar ölçeğinin alt boyutları olan, otorite ve doğruluk boyutu $\left(\mathrm{r}=0,294 ;{ }^{* *} \mathrm{P}<0,01\right)$, bilginin kaynağ boyutu $\left(\mathrm{r}=0,324 ;{ }^{* *} \mathrm{P}<0,01\right)$, bilgi üretme süreci $\left(\mathrm{r}=0,326 ;{ }^{* *} \mathrm{P}<\right.$ $0,01)$, akıl yürütme boyutu $\left(\mathrm{r}=0,367 ;{ }^{*} \mathrm{P}<0,01\right)$, ve bilginin değişirliği boyutu $\left(\mathrm{r}=0,268 ;{ }^{* *} \mathrm{P}<0,01\right)$ arasında istatistiksel olarak pozitif yönlü bir ilişki olduğunu göstermektedir.

Sınıf öğretmeni adaylarının teknolojiye karşı tutumlarını tahmin etmede kullanılan epistemolojik inançlar ölçeğinin alt boyutları sonuçlarının hiyerarşik çoklu regresyon analiz sonuçları Tablo 5'de verilmiştir.

Tablo 6. Eş Zamanlı Hiyerarşik Çoklu Regresyon Analiz Sonuçları

\begin{tabular}{cccl}
\hline Değişkenler & B & SHB & $\beta$ \\
\hline Model 1. Ak1l Yürütme & 1,353 & 0,253 & $0,287^{*}$ \\
\hline Model 2. Ak1l Yürütme & 1,166 & 0,302 & $0,247^{*}$ \\
Otorite ve doğruluk & 0,253 & 0,207 & 0,720 \\
\hline Model 3. Ak1l Yürütme & 0,567 & 0,137 & $0,222^{*}$ \\
Otorite ve doğruluk & 0,831 & 0,133 & 0,326 \\
Bilginin kaynağ1 & 0,540 & 0,139 & $0,212^{*}$ \\
\hline Model 4. Ak1l Yürütme & 1,011 & 0,347 & $0,214^{*}$ \\
Otorite ve doğruluk & 0,186 & 0,214 & 0,057 \\
Bilginin kaynağ1 & 0,256 & 0,282 & 0,066 \\
Bilgi üretme süreci & 0,519 & 0,141 & $0,203^{*}$ \\
\hline Model 5. Akıl Yürütme & 1,032 & 0,348 & $0,219^{*}$ \\
Otorite ve doğruluk & 0,220 & 0,217 & 0,068 \\
Bilginin kaynağ & 0,447 & 0,353 & 0,115 \\
Bilgi üretme süreci & 0,534 & 0,142 & $0,209^{*}$ \\
Bilginin değişirliği & $-0,354$ & 0,391 & $-0,077$ \\
\hline
\end{tabular}

Not: B, regresyon kat sayısi; SHB, B deki standart hata; $\beta$, standart regresyon kat sayısı. F:14,779, P:0,00 Ayarlanmış $\mathrm{R}^{2}: 0,173,{ }^{*} \mathrm{P}<0,05$

Tablo 6 de görüldüğü gibi sınıf öğretmeni adaylarının epistemolojik inançlar ölçeğinin alt boyutlarının tamamı modelde tahmin değişkeni olarak yer aldığında akıl yürütme boyutu ile bilgi üretme süreci alt boyutlarından alınan puanların teknolojiye karşı tutumlarını tahmin etmede istatistiksel olarak anlamlı bir katkısı varken diğer boyutların istatistiksel olarak anlamlı bir katkılarının olmadığı görülmektedir. 
Tablo 7. Akıl Yürütme Alt Boyutu İçin Regresyon Analiz Sonuçları

\begin{tabular}{llll}
\hline Değişken & B & SHB & $\beta$ \\
\hline Akıl Yürütme & 1,732 & 0,242 & $0,367^{* *}$ \\
Sabit & 69,291 & 2,758 & \\
\hline
\end{tabular}

Not: B, regresyon kat sayısi; SHB, B deki standart hata; $\beta$, standart regresyon kat sayısı. Çoklu $R=0,367, R^{2}=0,135$, ayarlanmış $R^{2}=0,132 .{ }^{* *} P<0,01$

Tablo 8. Bilgiyi Üretme Süreci Alt Boyutu İçin Regresyon Analiz Sonuçları

\begin{tabular}{lclc}
\hline Değişken & $\mathrm{B}$ & SHB & $\beta$ \\
\hline Epistemolojik İnanç & 0,831 & 0,133 & $0,326^{* *}$ \\
Sabit & 69,209 & 3,147 & \\
\hline
\end{tabular}

Not: $B$, regresyon kat sayısi; SHB, B deki standart hata; $\beta$, standart regresyon kat sayısı. Çoklu $R=0,326, R^{2}=0,106$, ayarlanmış $R^{2}=0,104 .{ }^{* *} P<0,01$

Tablo 7 ve 8 'de sınıf öğretmeni adaylarının epistemolojik inançlar ölçeğinin akıl yürütme boyutu için ayarlanmış $R^{2}$ değerinin 0,132 olması, öğretmen adaylarının teknolojiye karşı tutumlarındaki değişimin \% 13,2 sinin bu alt boyut tarafından kaynaklandığını ve bilgiyi üretme süreci boyutu için ayarlanmış $\mathrm{R}^{2}$ değerinin 0,104 olması, öğretmen adaylarının teknolojiye karşı tutumlarındaki değişimin \% 10,4 ünün bu alt boyut tarafından kaynaklandığını göstermektedir.

\section{Sonuç}

Çalışmada sınıf öğretmeni adaylarının epistemolojik inanç ve üstbiliş ölçeklerinden aldıkları puanlar ile teknoloji tutum ölçeğinden aldıkları puanlar arasında anlamlı bir ilişki olduğu ve öğretmen adaylarının teknolojiye karşı tutumlarındaki değişimin \%22,7'sinin sahip oldukları epistemolojik inançlarından ve üst-bilişlerinden kaynaklandığ görülmektedir. Bu açıdan sınıf öğretmeni adaylarının meslek yaşamındaki teknolojiyi kullanma noktasında epistemolojik inançları ve üst-bilişlerinin önemli olduğu görülmektedir.

Epistemolojik inanç bireyin bir bilgiyi edinme sırasındaki inançlarını ifade eder. Öğretmenlerin derslerinde teknolojiyi kullanabilmeleri için öncelikle kullanacakları o teknolojik materyal hakkında teorik bilgiye sahip olmaları gerekir. Bu bilgiyi edinirken ki olumlu epistemolojik inançları teknolojiye karşı olumlu tutum geliştirmeleri açısından önemlidir. Bu sebeple epistemolojik inanç teknolojiye karşı olumlu bir tutum 
geliştirebilmekle yakından ilişkilidir. Çalışmamızda sınıf öğretmeni adaylarının epistemolojik inançları ile teknolojiye karşı tutumları arasında $p<0,01$ düzeyinde ve istatiksel olarak pozitif yönlü bir ilişki söz konusudur. Ayrıca epistemolojik inançlar değişkeni sınıf öğretmeni adaylarının teknolojiye karşı tutumlarındaki değişimin \%16,3'ünü açıklamaktadır. Çalışmamızda ortaya çıkan sonuçla aynı sonucu veren bir başka çalışmada mevcuttur (İlhan, Demir ve Arslan, 2013).

Öğretmenlerin derslerinde konuya, öğrencinin seviyesine uygun teknolojik materyali seçebilmeleri ve bu materyali sınıf ortamında kullanabilmeleri için bu konuyla alakalı akıl yürütmeleri gerekir. Epistemolojik inançlar ölçeğinin alt boyutlarından olan akıl yürütme boyutu sınıf öğretmeni adaylarının teknolojiye karşı tutumlarındaki değişimin \%13,2'sini karşılamaktadır. Ayrıca öğretmenlerin derslerinde belirledikleri teknolojik materyali planladıkları gibi kullanabilmeleri için akıl yürütmenin yanında bilgiyi de üretmeleri gerekir bu durum ise öğretmenlerin bilgiyi üretme süreci ile yakından alakalıdır. Epistemolojik inançlar ölçeğinin alt boyutlarından olan bilgiyi üretme süreci boyutu sınıf öğretmeni adaylarının teknolojiye karşı tutumlarındaki değişimin \%10,4'ünü karşılamaktadır.

Üst-biliş bireyin bilgiyi edinme sürecindeki gerçekleşen olayların farkında olmasıdır. Öğretmenlerin belirledikleri teknolojik materyali nasıl kullanacaklarını bilmeleri materyalden etkin bir şekilde yararlanabilmeleri için önemlidir. $\mathrm{Bu}$ bilgiyi nasıl edindiklerinin farkında olmaları öğretmenlerin sahip olduğu üst-biliş düzeyleri ile yakından ilişkilidir. Çalışmamızda sınıf öğretmeni adaylarının üst-bilişleri ile teknolojiye karşı tutumları arasında $\mathrm{p}<0,01$ düzeyinde ve istatiksel olarak pozitif yönlü bir ilişki bulunmuştur. Ayrıca üst-biliş değişkeni sınıf öğretmeni adaylarının teknolojiye karşı tutumlarındaki değişimin \%8,3'ünü açıklamaktadır. Bakioğlu, Alkış Küçükaydın, Karamustafaoğlu, Uluçınar Sağır, Akman, Ersanlı ve Çakır (2015) yaptıkları çalışmada bizim çalışmamıza benzer sonuçlar bulmuşlardır.

\section{Kaynakça}

Acat, M.B., Tüken, G. ve Karadağ, E.(2010), Bilimsel Epistemolojik İnançlar Ölçeği: Türk Kültürüne Uyarlama, Dil Geçerliği ve Faktör Yapısının İncelenmesi, Türk Fen Eğitimi Dergisi, Yı1 7, Say1 4.

Bakioğlu, B., Alkış Küçükaydın, M., Karamustafaoğlu, O., Uluçınar Sağır, Ş., Akman, E., Ersanlı, E., Çakır, R. (2015), Öğretmen Adaylarının Bilişötesi Farkındalık Düzeyi, Problem Çözme Becerileri ve Teknoloji 
Tutumlarının İncelenmesi, Trakya Üniversitesi Eğitim Fakültesi Dergisi 2015, 1(1), 22-33

Baltacı, M. ve Akpınar,B. (2011). Web Tabanlı Öğretimin Öğrenenlerin Üstbiliş Farkındalık Düzeyine Etkisi. Mustafa Kemal Üniversitesi Sosyal Bilimler Enstitüsü Dergisi, 8(16), 319-333.

Bedel, E. F., Çakır, M. (2013). Okul Öncesi ve Biyoloji Öğretmen Adaylarında Bilişüstü Farkındalık ve Epistemolojik İnançların İncelenmesi. M.Ü. Atatürk Eğitim Fakültesi Eğitim Bilimleri Dergisi, 37, 84-98

Bromme, R., Pieschl, S. ve Stahl,E. (2010).Epistemological beliefs are standards for adaptive learning: a functional theory about epistemological beliefs and metacognition. Metacognition Learning, 5: $7-26$

Demir Ö. ve Doğanay A.(2009), "Sosyal Bilgiler Dersinde Bilişsel Koçluk Yoluyla Öğretilen Bilişsel Farkındalık Stratejilerinin Epistemolojik İnançlara Ve Kalıcılığa Etkisi", Çukurova Üniversitesi Eğitim Fakültesi Dergisi, vol.3, 54-68

Deryakulu, D. ve Büyüköztürk, S. (2005). Epistemolojik İnanç Ölçeğinin Faktör Yapısının Yeniden İncelenmesi: Cinsiyet ve Öğrenim Görülen Program Türüne Göre Epistemolojik İnançların Karşılaştırılması, Eğitim Araştırmaları, 5(18), 57-70.

Erdemir, N., Bakırcl, H. ve Eyduran E. (2009), Öğretmen Adaylarının Eğitimde Teknolojiyi Kullanabilme Özgüvenlerinin Tespiti, Türk Fen Eğitimi Dergisi, 6(3).

Gourgey, A. F. (2002). Metacognition in basic skills instruction. H. J. Hartman, (Ed.), Metacognition in learning and instruction: Theory, Research and Practice (17- 32). The Netherlands: Kluwer Academic Publishing.

İlhan, M., Demir, S ve Arslan, S. (2013), Öğretmen Adaylarının Bilgisayar Destekli Eğitime Yönelik Tutumları İle Epistemolojik İnançları Arasındaki İlişkinin İncelenmesi, Eğitim Teknolojisi, Kuram Ve Uygulama Cilt:3 Sayı:2

Karasar, N. (2000), Bilimsel Araştırma Yöntemleri, Ankara: Nobel Yayın Dağıtım.

Koç, M. (2004). Öğretim teknolojileri ve materyal gelistirme (ed. Y. Rauf) Temel kavramlar öğretim hedefleri ve araç seçimi. Ankara: Atlas Kitabevi sf.5.

Oktay, Senem ve Çakır, Recep (2012), İlköğretim Öğretmelerinin Teknoloji Kullanımları ve Teknolojiye Yönelik Tutumları Arasındaki İlişkinin İncelenmesi 
http://kongre.nigde.edu.tr/xufbmek/dosyalar/tam_metin/pdf/237930_05_2012-14_55_26.pdf) Erişim Tarihi:26.04.2015

Oktay, S. ve Çakır, R. (2013). Teknoloji Destekli Beyin Temelli Öğrenmenin Öğrencilerin Akademik Başarıları, Hatırlama Düzeyleri ve Üstbilişsel Farkındalık Düzeylerine Etkisi. Türk Fen Eğitimi Dergisi, $10(3)$.

Ozan, C. (2009). İlköğretim Sınıf Öğretmenlerinin Eğitim Teknolojileri Açısından Yeterlilikleri (Erzurum İli Örneği), Yayınlanmamış Yüksek Lisans Tezi, Atatürk Üniversitesi, Sosyal Bilimler Enstitüsü, Erzurum

Öztürk, E. ve Horzum, M.B. (2011), Teknolojik Pedagojik İçerik Bilgisi Ölçeği'nin Türkçeye Uyarlaması Ahi Evran Üniversitesi Eğitim Fakültesi Dergisi, Cilt 12, Sayı 3, Ağustos 2011, Sayfa 255-278

Sapancı, A. (2012). Öğretmen Adaylarının Epistemolojik İnançları ile Bilişüstü Düzeylerinin Akademik Başarıyla İlişkisi, Celal Bayar Üniversitesi Sosyal Bilimler Dergisi, 10(1).

Tüysüz, C., Karakuyu, Y., Bilgin, İ. (2008), Öğretmen Adaylarının Üst Biliş Düzeylerinin Bilişlerinin Belirlenmesi Abant İzzet Baysal Üniversitesi Sosyal Bilimler Enstitüsü Dergisi, , 17(2), 147-158

Yavuz, S. ve Coşkun, A.E. (2008), Sınıf Öğretmenliği Öğrencilerinin Eğitimde Teknoloji Kullanımına İlişkin Tutum ve Düşünceleri, Hacettepe Üniversitesi Eğitim Fakültesi Dergisi (H. U. Journal of Education) 34: 276-286

Yıldırım, S. (2007). Current utilization of ICT in Turkish basic education schools: A review of teacher's ICT use and barriers to integration." International Journal of Instructional Media, 34(2) 171-186. 
Y.KARAKUYU, A. KARAKUYU| 126 